\title{
Labyrinthe
}

19 | 2004 (3)

Le Bel Aujourd'hui

\section{Pour Jacques Derrida}

\section{Laurent Dubreuil}

\section{OpenEdition}

\section{Journals}

Édition électronique

URL : http://journals.openedition.org/labyrinthe/241

DOI : $10.4000 /$ labyrinthe.241

ISSN : 1950-6031

Éditeur

Hermann

Édition imprimée

Date de publication : 15 décembre 2004

Pagination : 89-92

Référence électronique

Laurent Dubreuil, «Pour Jacques Derrida », Labyrinthe [En ligne], 19 | 2004 (3), mis en ligne le 19 juin 2008, consulté le 24 avril 2019. URL : http://journals.openedition.org/labyrinthe/241 ; DOI : 10.4000/ labyrinthe. 241

Propriété intellectuelle 


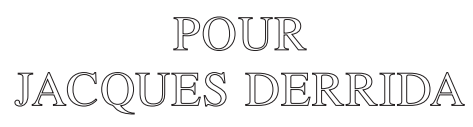

\author{
Laurent DuBREuIL \\ laurentdubreuil@wanadoo.fr
}

Cet aujourd'hui sera demain pour tant de temps. La nouvelle de la mort de Jacques Derrida s'est propagée dans la journée du 9 octobre 2004, jusqu'à se révéler dans la presse au cours de la soirée. Ce jour, 10 octobre, où Labyrinthe achève son dossier sur le bel aujourd'hui, nos derniers mots iront vers Derrida, pour sa mémoire et son œuvre.

Dès les années 1960, Derrida s'efforça de mener la critique la plus exigeante de l'appareil de conceptualité rationnelle. Il remit en cause la dichotomie, qu'il soupçonnait de cacher des hiérarchies par ellesmêmes discutables. Ne se contentant pas d'inverser la polarité (comme le faisait un Foucault), il revenait aux conditions mêmes du savoir philosophique. Sans renoncer à ce dernier, il porta d'emblée ${ }^{1}$ son regard sur les auteurs classiques (Hegel ou Platon) et sur ses contemporains (Heidegger ou Levinas). De même, il commentait, en plus des philosophes, les écrivains, les critiques littéraires, les linguistes, les anthropologues, les psychanalystes, sans prendre a priori une position surplombante ni englobante ${ }^{2}$. S'ajoutèrent ensuite à ces types de textes les domaines du droit, de la politique. Cet intérêt pour le «croisement» des disciplines, dans la perspective philosophique, le conduisit à jouer un rôle déterminant dans la constitution du Collège international de philosophie en 1983, et où l'intersection régit encore la distribution des séminaires. En marge des sciences humaines, la littérature eut une

\footnotetext{
1. Je fais ici référence à deux des trois ouvrages parus à Paris en 1967: L'Écriture et la différence (Seuil), De la Grammatologie (Minuit).

2. Par exemple, dans les deux ouvrages cités à la note précédente: Rousseau, Artaud, Bataille, Jean Rousset, Saussure, Lévi-Strauss, Freud.
} 
importance constante et déterminante pour Derrida, qui essaya des poétiques, que les livres faisaient varier. Traitant de la dissémination verbale dans Genet, il défait l'unité typographique de la page dans $G l a s^{3}$, où se lit un contrecoup sur la compréhension de Hegel. Dans La Carte postale ${ }^{4}$, et après les dialogues socratiques écrits par Platon, il élabore une philosophie épistolaire. Circonfession, au plus près de la jonction entre autobiographie et réflexion, se déroule en système périodique $^{5}$. Exposition philosophie, dialogisme, cursivité, collage s'associent dans Le Toucher ${ }^{6}$. Etc. Ce souci d'une écriture, allié à une réfutation de l'évidence et un violent doute à l'endroit du concept, s'organise en un fictif discours de la méthode, partout sous-jacent dans l'œuvre. Comme expérience, ce qui fut nommé «déconstruction» répondait ainsi à l'excédence qui caractérise la pensée littéraire.

Tout cela, qu'il nous rapprit, vaut et vit pour tous les jours comme aujourd'hui, dans tous ceux qui font l'effort de penser à leur tour. Depuis cette posture difficile, Derrida développa des hypothèses, des problèmes, des hantises comme la différence, le pharmakon, l'intrication du don (entre gift et Gift, cadeau et poison), l'impossible et l'événement, etc. Les analyses, développées chaque fois dans une minutie et une rigueur difficiles, méritent plus que jamais d'être comprises et altérées. Une continuation métamorphique est un hommage plus nécessaire que le simple devenir-patrimonial, ou même la seule action de grâce.

Prendre acte en continuant fut rarement aussi mal aisé qu'avec la philosophie de Derrida. À cause de son génie extrême, évidemment, et de sa nature quasi suspensive, également. Mais en outre parce que Derrida fut si entouré de haine qu'il était comme odieux de ne pas infiniment saluer l'œuvre. Quand Derrida ne cessa de réfuter les oppositions pures, certains réussirent à miner le terrain de la discussion: choisissez entre le pro et le contra ${ }^{7}$. De son vivant, Jacques Derrida aura

\footnotetext{
3. Paris, Galilée, 1974.

4. La Carte postale. De Socrate à Freud et au-delà, Paris, Flammarion, 1980.

5. Circonfession dans l'ouvrage de Geoffrey Bennington, Jacques Derrida, Paris, Seuil, 1991. Hélène Cixous signe un commentaire de ce texte singulier dans son Portrait de Jacques Derrida en jeune saint juif, Paris, Galilée, 2001.

6. Le Toucher. Jean-Luc Nancy, Paris, Galilée, 2000.

7. Un exemple ridicule en était livré dans le compte rendu que je fis pour Labyrinthe sur un ouvrage collectif où Derrida était associé aux dark forces de l'irrationnel ( $\mathrm{n}^{\circ} 14,2003$, p. 115).
} 


\section{Pour Jacques Derrida}

connu des honneurs, suscité mille commentaires, formé et influencé directement des générations. À proportion, l'individu et son travail ont été détestés, ridiculisés. La haine, généralement si vulgaire, culmine aujourd'hui en France dans le positivisme réactionnaire qui régit majoritairement les études littéraires et philosophiques. Depuis quelques années au moins, la détestation de Derrida formait d'ailleurs un sujet de conversation très consensuel entre universitaires, lorsque l'interlocution avait épuisé les préoccupations ordinaires (jeux de postes et de pouvoir dit symbolique). Avec la mort de Deleuze, on avait souvent droit à une variante nauséeuse, où les anciens détracteurs de L'AntiEdipe en appelaient sans honte aux mânes de Gilles contre Jacques ${ }^{8}$. La mort transformant les opinions (en l'occurrence, pour le pire), il est vraisemblable que les «chiens vivants » profitent du décès pour verser quelques fausses larmes de sang. Rien n'empêche non plus la perpétuation de l'abhorration, comme un jeu rémanent. Dans les deux cas, on évitera soigneusement d'envisager l'aujourd'hui philosophique, et d'aller après lui. - Du moins restera-t-il l'œuvre, telle que je n'ai aucun doute sur son éternité humaine. Je l'avoue, je suis là moins incertain que son auteur qui semblait parfois hésiter, sous les assauts conjugués des haines et des gloires?.

Cette conviction mienne, si banale, si indispensable à dire, s'est formée d'abord dans le jeune homme qui tentait au lycée de lire L'Écriture et la différence. La découverte eut lieu ensuite, avec Glas. En plus des professeurs de la khâgne qui m'apprenaient la philosophie, les livres de Derrida m'enseignaient autrement. En France, nous ne sommes pas si nombreux, mais tout de même, ce que j'ai connu là fut partagé par beaucoup, je crois. Derrida nous apparaissait comme Platon, Aristote, Descartes ou Pascal; avec cette différence qu'il vivait. Nous allâmes l'écouter une nuit qu'il passait à Lyon: j'avais dix-neuf ans, et nous nous disions «c'est donc lui », lui en plus de ses livres. Plus tard, j'eus la chance de le côtoyer un peu. Je ne le dis pas sans réticence, car je sais qu'il pousse aujourd'hui déjà des centaines d'amis

\footnotetext{
8. Je ne parle pas ici des héritiers directs de l'un et l'autre philosophe, qui ont gardé entre eux une distance continuelle, selon l'interdit remotivé du monothéisme, contre l'adoration de plusieurs idoles. 9. Voir cette étrange note où Derrida refusait d'être rapprochés d'auteurs reconnus comme Heidegger, «D'un texte à l'écart», Les Temps modernes n²84, 1970. Lors d'une émission télévisée («Le Gai savoir», mai 2002), le philosophe avait encore rechigné à admettre qu'une œuvre philosophique puisse désormais durer vraiment.
} 
posthumes. Mais il serait injuste de taire que j'ai également fréquenté l'homme qu'il fut, grâce à l'amitié de l'amie, Hélène Cixous. Je parlais avec lui dans des fêtes, des célébrations, des anniversaires, des jours de l'an où se souhaitait le meilleur. Et dans ces autres sortes d'invitations: les séminaires, les colloques, qui représentaient une part dévorante de ses jours. Au cours des années, par six ou sept fois, en public, j'ai dû lui poser de longues questions, à l'instar de la terre entière, qui l'interrogeait sans arrêt. "Question de responsabilité ${ }^{10}$ », il écoutait et répondait. Dans toutes les circonstances où j'ai connu Jacques Derrida, il gardait cette grandeur, cette attention, cette gentillesse. «C'était donc lui », un héroïsme de la pensée, et la générosité. La douleur est là, elle commence abstraitement, elle s'acère peu à peu.

10. Tel fut à peu près le titre générique de son séminaire à l'EHESS au cours de la dernière décennie. 